\title{
Replacing the (inefficient) manual runoff sampling method used in Brazil - a prototype
}

\section{sample splitter}

\author{
Alessandro Samuel-Rosa ${ }^{1 *} \oplus$, Jean Michel Moura-Bueno ${ }^{2}$, Ricardo Simão Diniz Dalmolin²®
}

\author{
'Universidade Tecnológica Federal do Paraná - Lab. de \\ Pedometria, Prolongamento da R. Cerejeira, $\mathrm{s} / \mathrm{n}-85892-$ \\ 000 - Santa Helena, PR - Brasil. \\ 2Universidade Federal de Santa Maria/CCR - Depto. de \\ Solos, Av. Roraima, 1000, Prédio 42, Sala 3309 - 97105- \\ 900 - Santa Maria, RS - Brasil. \\ *Corresponding author <alessandrorosa@utfpr.edu.br>
}

Edited by: Silvia del Carmen Imhoff

Received April 24, 2019

Accepted January 07, 2020

\begin{abstract}
The method used to sample the runoff collected from soil erosion plots can be a significant source of error. In this study, we performed a laboratory experiment to evaluate the efficiency of the runoff sampling method most commonly used in Brazil. It is based on the manual homogenization and sampling of the collected runoff. Using soil material with 583 $\mathrm{g} \mathrm{kg}^{-1}$ of sand and $89 \mathrm{~g} \mathrm{~kg}^{-1}$ of clay, the manual sampling method was tested for its ability to produce representative samples of artificial suspensions with a concentration of 2, 10 and 50 $\mathrm{g} \mathrm{L}^{-1}$ of total solids. An underestimation of $30 \%$ or more of the concentration of total solids was observed, with a variation of the same magnitude (CV between 20 and $45 \%$ ). We then developed a prototype sample splitter to replace the manual sampling method and tested it using the same artificial suspensions. The splitter was efficient in producing samples representative of the artificial suspensions, even without altering the particle size distribution of the total solids. Both absolute percentage errors $(\mid<5 \%)$ ) and the variation between five replicates (CV $<3 \%$ ) were small. The problems with the manual method are due to the inefficient homogenization that facilitates the differential sedimentation of particles of different sizes. If these problems are also found in other areas, then the prototype that we developed is a reasonable alternative.
\end{abstract}

Keywords: erosion monitoring, soil loss, sandy soil, uncertainty

\section{Introduction}

Soil erosion is one of the major concerns of soil scientists (Panagos et al., 2017). Proof of this are the many erosion plots distributed around the globe (GarcíaRuiz et al., 2015; Anache et al., 2017; Silva et al., 2018). However, the quality of the data from erosion plots has often been questioned on account of the great variability that attaches to the use of a diversity of methods and monitoring strategies (Nearing et al., 1999; Boix-Fayos et al., 2006; García-Ruiz et al., 2015; Poesen, 2018). Lack of resources for monitoring a period longer than 5-10 years to obtain more consistent data has also been detrimental (Anache et al., 2017) - the poorer the data, the greater the uncertainty about the magnitude of the true soil losses.

The method used to sample the runoff collected from erosion plots can be a major source of error (Kinnell, 2016): sampling the collected runoff requires that it first be homogenized; however, accomplishing this is difficult when solid particles of different sizes and densities are present. Researchers from various places around the world have already shown that manual sampling methods are among those methods that suffer most from this problem, commonly underestimating soil losses (Lang, 1992; Zöbisch et al., 1996; Ciesiolka et al., 2006; Nikkami, 2012; Huang et al., 2019). Curiously, this literature seems to have been largely ignored in Brazil, where a manual sampling method (Veiga and Wildner, 1993) has remained the standard (Tengberg et al., 1997; Eltz et al., 2001; Volk and Cogo, 2009; Merten et al., 2015; Corrêa et al., 2016).

Advanced sampling (Nikkami, 2012; Todisco et al., 2012) and correction methods (Ciesiolka et al., 2006;
Huang et al., 2019) were developed to circumvent the issues described above. The drawback is that they still require the collected runoff to be homogenized before sampling. An alternative is to use sample splitters such as cone and churn splitters (Capel et al., 1995; Horowitz et al., 2001). Sample splitters are designed to produce samples with a constitution very similar to the original suspension without the need for prior homogenization. However, most of the splitters currently in existence were designed for sampling suspensions with a low concentration of total solids (Capel et al., 1995; Horowitz et al., 2001).

The aim of this paper was twofold. First, to add to the existing literature in this field by showing that the manual runoff sampling method used in Brazil also underestimates soil losses. Second, to present a prototype sample splitter - to replace the manual sampling method - and its performance. Both methods were analyzed through a laboratory experiment using sandy soil material.

\section{Materials and Methods}

\section{Background}

Our research group has recently been involved in designing and implementing an experiment to monitor soil erosion under natural rainfall in marginal areas in southern Brazil. In such experiments, soil losses are measured after rainfall events in collection tanks placed at the exit of runoff plots (Figure 1A-D). The size of collection tanks is determined by the size of runoff plots and expected intensity of rainfall events. Large plots generally contain a flume with a multislot divisor 
A
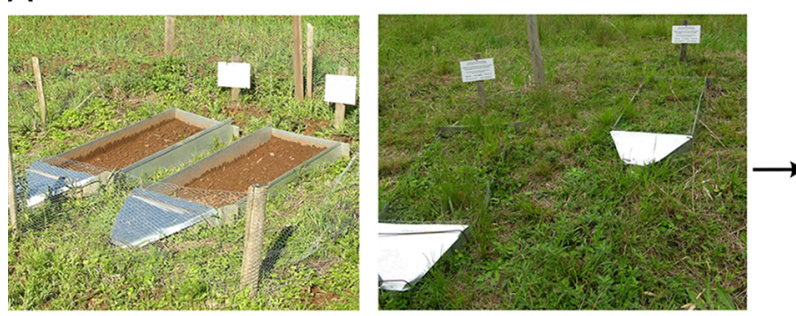

B

C

D
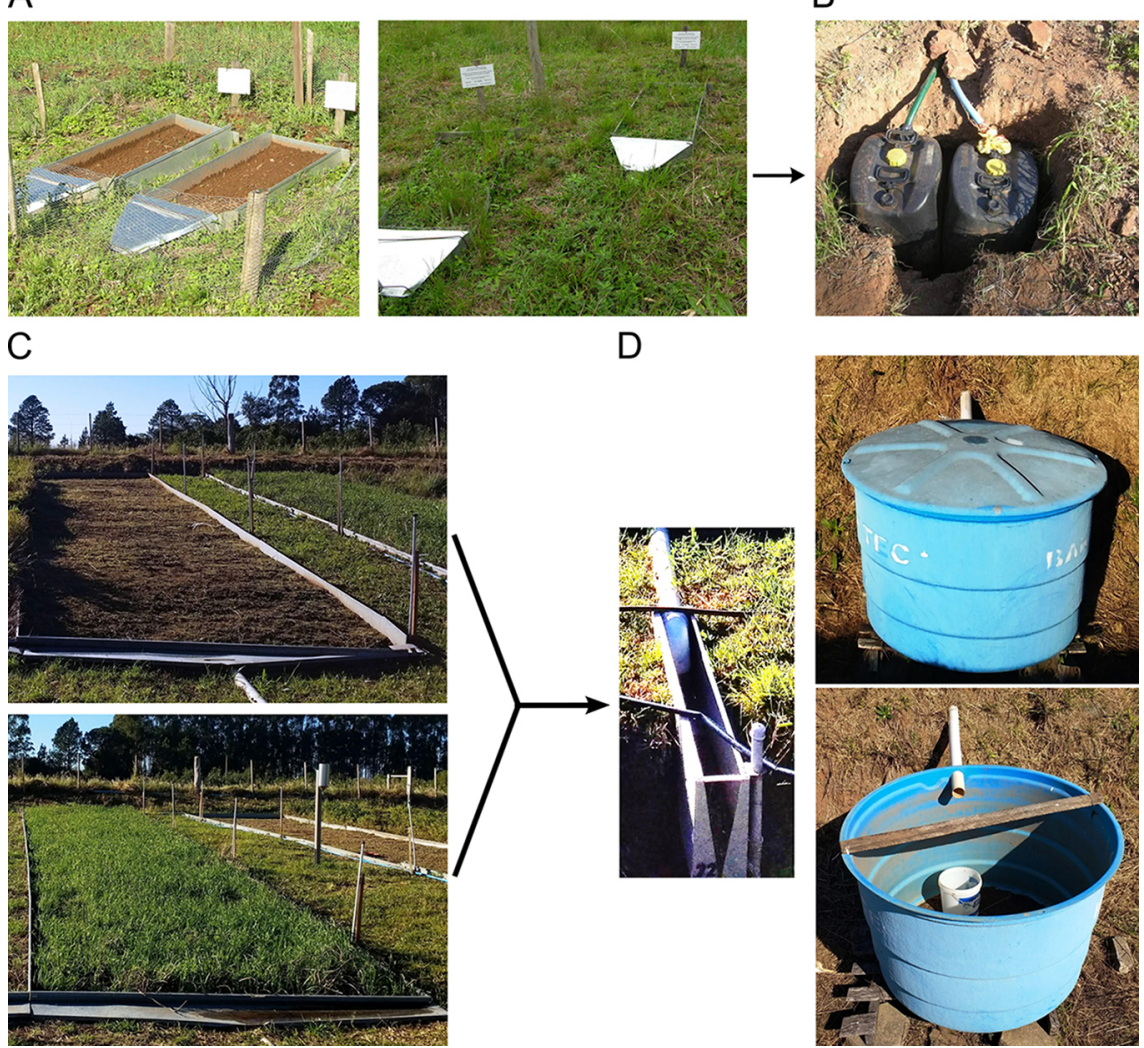

Figure 1 - Soil erosion monitoring plots under natural rainfall conditions encountered in Brazil. In both small (A) and large (C) scale erosion studies the setup consists of a rectangular runoff plot $-0.5 \times 1.0 \mathrm{~m}$ and $3.5 \times 22 \mathrm{~m}$, respectively - with a triangle shaped collector at its lower end and a reservoir where the runoff and sediment are collected (B and D) $-50 \mathrm{~L}$ and $1000 \mathrm{~L}$, respectively.

at the exit to subdivide the runoff and avoid overflow in the collection tanks. Nevertheless, in most cases, the volume of runoff and sediment collected in the tanks is so large that it needs to be sub-sampled. During the design of our experiment, we discovered that a manual sampling method is used in Brazil for this purpose. The international literature suggests that manual sampling methods tend to underestimate soil losses. Thus, this represented to us a gap/weakness in soil erosion monitoring research in Brazil. The section evaluating the manual sampling method describes how we assessed the performance of the sampling method used in Brazil. Since our findings agreed with the existing international literature - and we were not satisfied with the existing solutions -, we designed and tested a sample splitter that could replace the manual runoff sampling method. Constructive details and performance assessments are described in the section 'A prototype sample splitter'.

\section{Soil material}

The two sample splitting methods - manual and splitter - were evaluated in the laboratory using artificial suspensions. These suspensions were composed of distilled water and fine soil material formulated to simulate runoff and sediment samples. The soil material was collected from the upper part $(0-20 \mathrm{~cm}$ depth) of the A horizon of a soil profile derived from sedimentary rocks in the Santa Maria Formation. Located at $-29^{\circ} 42^{\prime} 47.01^{\prime \prime}$ $\mathrm{N}$ and $-53^{\circ} 42^{\prime} 43.36^{\prime \prime} \mathrm{E}$, altitude of $90 \mathrm{~m}$ the profile had no apparent anthropic use, and was classified as an Argissolo Vermelho-Amarelo Distrófico típico in the 2018 Brazilian classification code and as a Rhodic Acrisol in the 2015 update of the IUSS international classification code. With an A-E-Bt-C horizon sequence, the clay content is very low in the topsoil and increases considerably with depth, with a direct effect on the soil bulk density and porosity. The low content of basic cations, phosphorus and organic matter reflect the low availability of plant nutrients in the soil parent material (Tables 1 and 2), and the analytic data are available in the Free Brazilian Repository for Open Soil Data (FEBR, www.ufsm.br/febr), dataset ctb0013. Similar characteristics can be found in the topsoil of a large portion of the Central Depression region in the state of Rio Grande do Sul (Figure 2), having been the target of many erosion monitoring studies (Cogo et al., 1984; Eltz et al., 2001; Volk and Cogo, 2009).

The collected soil material was air-dried, crushed and passed through a $2-\mathrm{mm}$ sieve. The particle size distribution of the resulting fine soil material, used 
Table 1 - Physical properties of the soil profile horizons.

\begin{tabular}{|c|c|c|c|c|c|c|c|c|}
\hline Horizon & Boundaries & Coarse sand & Fine sand & Clay & Bulk density & Particle density & Macroporosity & Microporosity \\
\hline & $\mathrm{cm}$ & 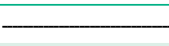 & $-\mathrm{g} \mathrm{kg}^{-1}$ & 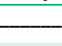 & $\mathrm{g}$ & $m^{-3}$ & $-\mathrm{m}^{3}$ & $n^{-3}$ \\
\hline A & $0-40$ & 140 & 441 & 73 & 1.41 & 2.65 & 0.215 & 0.25 \\
\hline$E$ & $40-60$ & 108 & 414 & 70 & 1.68 & 2.63 & 0.133 & 0.23 \\
\hline $\mathrm{Bt}$ & $60-90$ & 80 & 307 & 262 & 1.65 & 2.69 & 0.060 & 0.33 \\
\hline C & $90-120$ & 60 & 298 & 282 & 1.55 & 2.76 & 0.040 & 0.40 \\
\hline
\end{tabular}

Table 2 - Chemical properties of the soil profile horizons.

\begin{tabular}{|c|c|c|c|c|c|c|c|c|}
\hline Horizon & Boundaries & $\mathrm{pH}$ & $\mathrm{Ca}^{2+}$ & $\mathrm{Mg}^{2+}$ & $\mathrm{K}^{+}$ & $\mathrm{H}+\mathrm{Al}$ & $\mathrm{P}_{2} \mathrm{O}_{5}$ & Organic matter \\
\hline & $\mathrm{cm}$ & & & - & & & $\mathrm{mg} \mathrm{L}^{-1}$ & $\mathrm{~g} \mathrm{~kg}^{-1}$ \\
\hline A & $0-40$ & 4.6 & 2.00 & 0.35 & 0.05 & 2.20 & 1.5 & 12 \\
\hline$E$ & $40-60$ & 4.5 & 1.90 & 0.25 & 0.07 & 1.37 & 0.7 & 6 \\
\hline Bt & $60-90$ & 4.6 & 2.85 & 0.80 & 0.04 & 2.51 & 0.7 & 4 \\
\hline C & $90-120$ & 4.7 & 2.35 & 1.50 & 0.05 & 2.56 & 0.7 & 3 \\
\hline
\end{tabular}

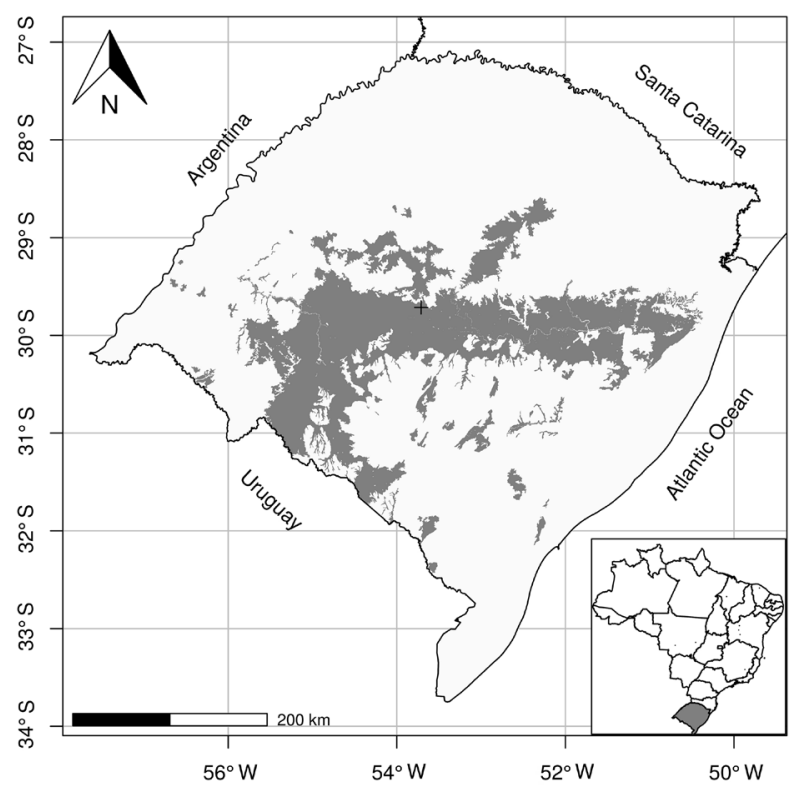

Figure 2 - Area of the state of Rio Grande do Sul with a superficial soil layer similar in texture to the soil material used in this study. The cross near the center of the state indicates the location where the soil material was collected.

to prepare the artificial suspensions, was determined using three samples weighing approximately $20 \mathrm{~g}$ each. The total clay content $1<0.002 \mathrm{~mm}$ diameter $)$ was determined via the pipette method after chemical dispersion and mechanical disintegration. The first was achieved using $1 \mathrm{~mol} \mathrm{~L}^{-1}$ sodium hydroxide $(\mathrm{NaOH})$. The latter consisted of horizontal stirring for $4 \mathrm{~h}$ at 120 cycles per min in the presence of two nylon spheres (diameter: $1.71 \mathrm{~cm}$; mass: $3.04 \mathrm{~g}$; density $\left.1.11 \mathrm{~g} \mathrm{~cm}^{-1}\right)$. The total sand content $(0.053-2.00 \mathrm{~mm}$ diameter) was determined via wet sieving. The total silt (0.002-0.053 mm diameter) content was determined by difference. According to these analyses, the particle size distribution of the fine soil material $(0-20 \mathrm{~cm})$ consisted of $583 \mathrm{~g} \mathrm{~kg}^{-1}$ of sand, 89 $\mathrm{g} \mathrm{kg}^{-1}$ of clay, and $328 \mathrm{~g} \mathrm{~kg}^{-1}$ of silt.

\section{Evaluating the manual sampling method}

The first laboratory experiment that we carried out aimed at assessing the efficiency of the manual method, i.e., its ability to produce representative samples of the artificial suspensions. The samples were expected to have a concentration of total solids approximately equivalent to that of the suspension from which they were obtained. Artificial suspensions with three concentrations of total solids were used in the following amounts: 2, 10 and $50 \mathrm{~g} \mathrm{~L}^{-1}$. They were prepared by adding the necessary mass of fine soil material to $3 \mathrm{~L}$ of distilled water in 10 L plastic containers (buckets) - such as those used in real world erosion monitoring studies (Figure 1D) - i.e, 6, 30, and $150 \mathrm{~g}$, respectively. Five buckets (replicates) were prepared for each concentration. In each bucket, one person homogenized and stirred the suspension with one hand. After 10 seconds, without stopping the homogenization, another person collected a sample by immersing a $250 \mathrm{~mL}$ beaker into the suspension (Figure $3 \mathrm{~A})$. The concentration of total solids in the samples of each artificial suspension was determined as a function of the sample volume and the mass of total solids measured after oven drying at $105^{\circ} \mathrm{C}$ until the water had completely evaporated.

The five samples from each of the three artificial suspensions were summarized by computing the mean, standard deviation, and coefficient of variation. The estimation error, $e_{i j}$, was computed from the difference between the concentration of total solids in an artificial suspension $j$ as estimated by a sample $i, \hat{y}_{i j}$, and the true concentration, $y_{j}$ i.e.,

$e_{i j}=\hat{y}_{i j}-y_{i}$

where $i=1,2, \ldots, n, n=5$, and $j$ is one of the three artificial suspensions. The percent mean estimation error (pME), defined as the percentage magnitude of the 
estimation error in relation to the true concentration in an artificial suspension $j$, was calculated by

$$
p M E_{j}=1 / 5 \sum_{i=1}^{n=5} e_{i j} / y_{i} \times 100
$$

Finally, the estimation errors were submitted to a one sample, two-tailed $t$-test to test if its mean was equal to zero $\left(\mathrm{H}_{0}: \mu=0\right)$ or, alternatively, less or greater than zero $\left(\mathrm{H}_{1}: \mu \neq 0\right)$. The $t$-statistic was given by

$$
t_{j}=\frac{\bar{e}_{j}}{s_{j} \sqrt{5}}
$$

where $s_{j}$ is the sample standard deviation of the estimation error. The exact $p$-value of the $t$-test was obtained from Student's $t$ cumulative distribution function (CDF) with $n-1$ degrees of freedom.

\section{A prototype sample splitter}

The prototype sample splitter was constructed with polyvinyl chloride (PVC) and wooden parts (Figure 3B and Figure 4). It is composed of a suspension reservoir, located on the upper part, which consists of a $300-\mathrm{mm}$ long, 75-mm diameter PVC plastic pipe with a maximum net capacity of $1 \mathrm{~L}$ of suspension. The bottom of the reservoir consists of a PVC internal domed end cap. A 15-mm diameter hole was drilled in the center of the cap to connect a 300-mm long, 15$\mathrm{mm}$ diameter PVC plastic pipe. The dome-shaped end cap helps direct the reservoir suspension to the smaller diameter pipe connected to the lower end. The function of this smaller diameter pipe is to direct the suspension in a continuous and concentrated flow to the splitting device, a Y-connector placed at its lower end. All parts are glued to each other using PVC-specific adhesive material. Since the splitter has two outlets, A and B, it produces two samples of the suspension at each splitting operation. Finally, the PVC parts were fixated on a wooden platform, leveled with both horizontal and vertical planes.
The sample splitter method was submitted to three laboratory tests. The first test aimed to evaluate if the volume of the suspension affects the performance of the splitter, specifically, its capacity to produce pairs of samples with approximately equivalent volumes. Four volumes of distilled water were evaluated - 100, 300, 500, and 1000 $\mathrm{mL}$ - using five replicates. For each repetition, the total volume of distilled water was poured into the splitter's reservoir at one time. The two resulting samples, $\mathrm{A}$ and $\mathrm{B}$, were collected in beakers and their volume determined using calibrated graduated cylinders. The estimation error and its ratio to the true value (half of the total volume of distilled water), both defined above, were calculated for both samples. Estimation errors were submitted to the one sample, two-tailed $t$-test as described for the manual method. In addition, the estimation errors of outlets $A$ and $B$ were tested for equality using the paired sample, twotailed $t$-test. The $t$-statistic was given by

$$
t_{j}=\frac{\bar{d}_{j}}{s_{d_{j}} \sqrt{5}}
$$

where $\bar{d}_{j}$ is the mean of differences between estimation errors of outlets $\mathrm{A}$ and $\mathrm{B}, s_{d j}$ the sample standard deviation of the differences, and $j$ one of the four volumes tested.

The second test to which the splitter method was submitted was the same as that applied to the manual method, i.e., an assessment of its ability to produce a representative sample of the artificial suspension. The same concentrations used to evaluate the manual method were employed, also with five replicates each. The artificial suspensions were prepared in 500-mL plastic containers. After vigorous shaking for 10 seconds, each suspension was poured into the splitter's reservoir at the same time and both samples, A and B, were collected in 250-mL beakers. The splitter was washed with distilled water after each repetition. The concentration of total solids in the samples was determined as that described for the manual method. The estimation errors were submitted to one and paired sample, two-tailed $t$-tests as above.

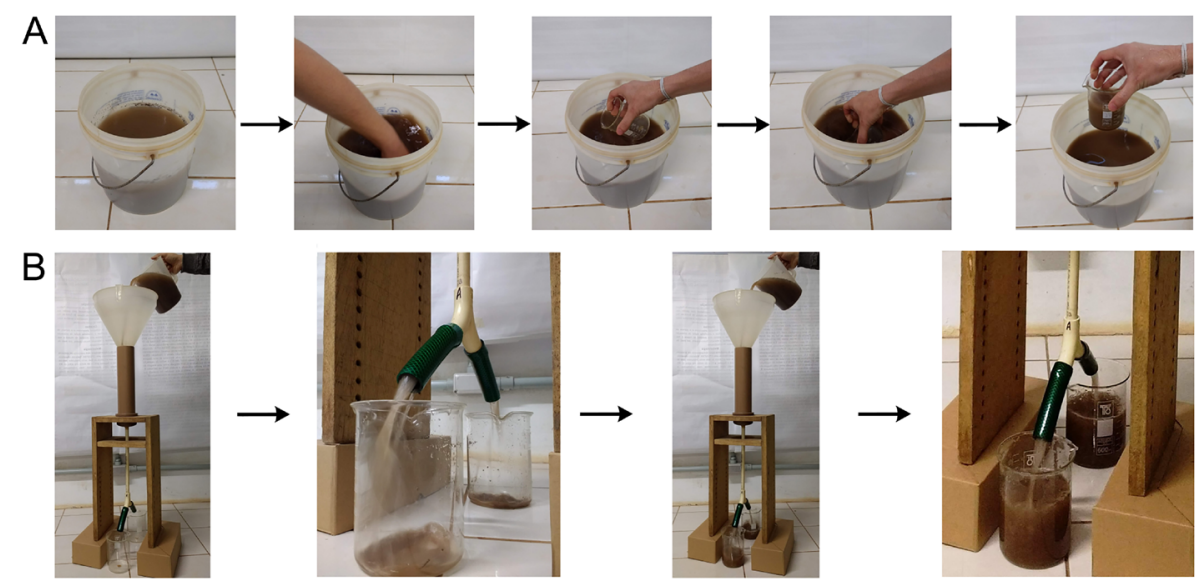

Figure 3 - Sampling the artificial suspensions using (A) the manual sampling method and (B) the prototype sample splitter. 


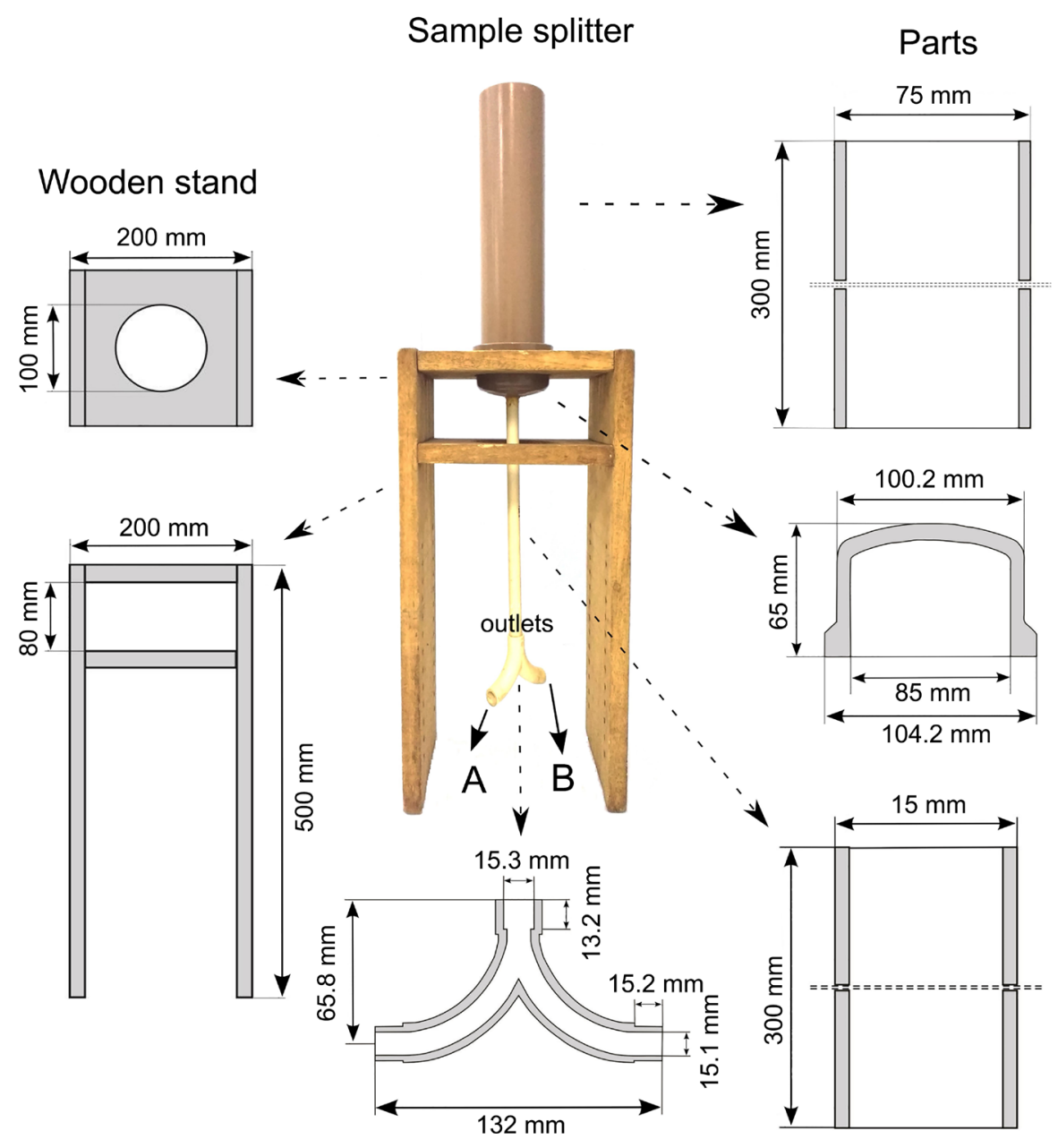

Figure 4 - Prototype sample splitter compared to the manual method. The constituent PVC and wooden parts and their dimensions (unscaled) are shown in detail.

Finally, the total solids contained in the samples produced by outlets $A$ and $B$ of the splitter were analyzed for particle size distribution. The same method used for the analysis of the soil material employed to produce the artificial suspensions was used. The aim of this test was to evaluate the capacity of the splitter to produce samples where the total solids have a size distribution approximately equivalent to that observed in the total solids of the artificial suspension. The one and paired sample, two-tailed $t$-tests were used to evaluate the estimation errors in the clay and sand content.

\section{Results and Discussion}

\section{Manual sampling method}

The test performed with the manual runoff sampling method showed that the resulting samples were not representative of the artificial suspensions used (Table 3). The mean concentration of total solids across the five replicates of all three artificial suspensions was
Table 3 - Concentration of total solids in five samples (S1, S2, ..., S5) obtained using the manual sampling method from three artificial suspensions with a known concentration of total solids of 2, 10 and $50 \mathrm{~g} \mathrm{~L}^{-1}$. Statistics: $\mathrm{SD}=$ standard deviation, $\mathrm{CV}=$ coefficient of variation, $\mathrm{pME}=$ percentage mean estimation error, $t_{1}=$ one-sample $t$-test statistic, $p_{1}=p$-value of the $t_{1}$-test.

\begin{tabular}{|c|c|c|c|}
\hline \multirow{2}{*}{ Data and statistics } & \multicolumn{3}{|c|}{ Concentration of total solids } \\
\hline & 2 & 10 & 50 \\
\hline & \multicolumn{3}{|c|}{$\longrightarrow \mathrm{g} \mathrm{L}^{-1} \longrightarrow$} \\
\hline S1 $\left(g \mathrm{~L}^{-1}\right)$ & 1.16 & 4.06 & 25.55 \\
\hline $\mathrm{S} 2\left(\mathrm{~g} \mathrm{~L}^{-1}\right)$ & 1.18 & 6.68 & 58.65 \\
\hline $\mathrm{S} 3\left(\mathrm{~g} \mathrm{~L}^{-1}\right)$ & 1.36 & 4.81 & 44.73 \\
\hline S4 $\left(\mathrm{g} \mathrm{L}^{-1}\right)$ & 2.01 & 4.26 & 32.36 \\
\hline $\mathrm{S} 5\left(\mathrm{~g} \mathrm{~L}^{-1}\right)$ & 0.98 & 4.62 & 16.98 \\
\hline Mean $\left(g \mathrm{~L}^{-1}\right)$ & 1.34 & 4.89 & 35.65 \\
\hline $\mathrm{SD}\left(\mathrm{g} \mathrm{L}^{-1}\right)$ & 0.40 & 1.05 & 16.38 \\
\hline CV (\%) & 29.82 & 21.39 & 45.93 \\
\hline pME (\%) & -33.10 & -51.14 & -28.69 \\
\hline$t_{1}$ & -3.7097 & -10.9415 & -1.9587 \\
\hline$p_{1}$ & 0.0207 & 0.0004 & 0.1217 \\
\hline
\end{tabular}


considerably lower than the target concentration $(2,10$ and $50 \mathrm{~g} \mathrm{~L}^{-1}$. This resulted in an average concentration underestimate of $30 \%$ or more as revealed by the pME. In addition, we observed a somewhat large variation in the concentration of total solids between the five replicates, the coefficients of variation ranging from $21 \%$ to $46 \%$. The larger the concentration of total solids in the suspension, the larger the variation observed between the estimates of the replicates. This happened because the more solid particles in a suspension, the more difficult its homogenization becomes, especially if the solids are dominated by coarse material (sand). These empirical findings - the first of their kind ever obtained in Brazil - agree with those reported by studies on manual runoff sampling methods carried out in other parts of the world over the last three decades (Lang, 1992; Zöbisch et al., 1996; Ciesiolka et al., 2006; Todisco et al., 2012; Kinnell, 2016). This agreement means that, irrespective of the experimental conditions, manual runoff sampling methods are inconsistent and inefficient when coarse particles (sand $>500 \mathrm{~g} \mathrm{~kg}^{-1}$ ) dominate the solid fraction. Brazilian researchers monitoring erosion in sandy soil should be aware of these severe drawbacks and use more appropriate runoff sampling methods.

The consistent underestimation of the concentration of total solids in a suspension by the manual sampling method suggests that real world soil losses could be considerably higher than those reported in the literature. In those areas of southern Brazil with coarse texture soil $-<100 \mathrm{~g} \mathrm{~kg}^{-1}$ of clay and $>500 \mathrm{~g} \mathrm{~kg}^{-1}$ of sand - similar to the soil material used to prepare the artificial suspensions for this study (Figure 2), soil losses could be underestimated by 30-50 \%. For example, according to Lanzanova et al. (2013), a standard (bare) soil erosion monitoring plot $/$ width $=3.5 \mathrm{~m}$, length $=$
$22 \mathrm{~m}$, slope $=0.055 \mathrm{~m} \mathrm{~m}^{-1}$ ) located near the place where we collected the soil material for this study lost about $2.5 \mathrm{Gg} \mathrm{ha}^{-1}$ of soil in 16 years. Based on the results of our laboratory experiment, the amount of soil lost in this plot could be as high as 3.6-5.0 $\mathrm{Gg} \mathrm{ha}^{-1}$.

Despite corroboration of our results by articles in the international literature, attention must be paid to the fact that they are based on one-person sampling. Zöbisch et al. (1996) evaluated five experienced professionals and observed estimation errors between 5 and $83 \%$. Since the variation observed by Zöbisch et al. (1996) agrees with our results, this suggests our experiment should be reproduced by other research groups, as the results may be affected by the person responsible for sampling the suspension. Furthermore, this experiment does not reflect all field conditions found throughout Brazil and should be repeated under other soil - in terms of particle size distribution - and experimental conditions to produce more representative results. This is especially important so that an equation can be computed to correct soil loss estimates if the manual sampling method proves to fail under a wide diversity of conditions.

\section{Sample splitter method}

The results of the first test performed with the prototype sample splitter showed that its efficiency is not affected by the volume of water (Table 4). Both outlets A and B produced samples with similar volumes. However, the splitting process seems to become less efficient as the volume of water decreases. The largest errors were observed when the volume of water was $100 \mathrm{~mL}$, possibly due to the swirling effect of the water inside the 15-mm diameter PVC plastic pipe connected to the lower end of the reservoir. The function of this pipe is to direct the water in a continuous and

Table 4 - Volume of the five samples ( $S 1, S 2, \ldots, S 5)$ produced by outlets A and B of the sample splitter for initial volumes of $100,300,500$ and $1000 \mathrm{~mL}$. Statistics: $\mathrm{SD}=$ standard deviation, $\mathrm{CV}=$ coefficient of variation, $\mathrm{pME}=$ percentage mean estimation error, $t_{1}$ and $t_{2}=$ one and two-sample t-test statistic, $p_{1}$ and $p_{2}=p$-value of the $t_{1}$ and $t_{2}$-test.

\begin{tabular}{|c|c|c|c|c|c|c|c|c|}
\hline \multirow{3}{*}{ Data and statistics } & \multicolumn{8}{|c|}{ Initial sample volume and splitter outlet } \\
\hline & \multicolumn{2}{|c|}{100} & \multicolumn{2}{|c|}{300} & \multicolumn{2}{|c|}{500} & \multicolumn{2}{|c|}{1000} \\
\hline & A & B & A & B & A & $B$ & A & $B$ \\
\hline S1 (mL) & 48.00 & 50.00 & 155.00 & 145.00 & 245.00 & 254.00 & 507.00 & 484.50 \\
\hline S2 (mL) & 44.00 & 54.00 & 144.00 & 156.00 & 261.00 & 239.00 & 457.00 & 534.50 \\
\hline S3 (mL) & 47.00 & 51.50 & 153.00 & 146.00 & 248.50 & 251.00 & 492.50 & 498.00 \\
\hline $\mathrm{S} 4(\mathrm{~mL})$ & 45.50 & 53.00 & 150.00 & 150.00 & 256.00 & 244.00 & 512.50 & 477.50 \\
\hline S5 (mL) & 42.00 & 57.00 & 146.00 & 154.00 & 249.50 & 250.00 & 525.50 & 464.00 \\
\hline Mean (mL) & 45.30 & 53.10 & 149.60 & 150.20 & 252.00 & 247.60 & 498.90 & 491.70 \\
\hline $\mathrm{SD}(\mathrm{mL})$ & 2.39 & 2.66 & 4.62 & 4.82 & 6.41 & 6.02 & 26.24 & 26.89 \\
\hline CV (\%) & 5.27 & 5.00 & 3.09 & 3.21 & 2.54 & 2.43 & 5.26 & 5.47 \\
\hline pME (\%) & -9.40 & 6.20 & -0.27 & 0.13 & 0.80 & -0.96 & -0.22 & -1.66 \\
\hline$t_{1}$ & -4.4020 & 2.6110 & -0.1940 & 0.0930 & 0.6970 & -0.8910 & -0.0940 & -0.690 \\
\hline$p_{1}$ & 0.0117 & 0.0594 & 0.8558 & 0.9305 & 0.5240 & 0.4234 & 0.9298 & 0.528 \\
\hline$t_{2}$ & \multicolumn{2}{|c|}{-3.4660} & \multicolumn{2}{|c|}{-0.1420} & \multicolumn{2}{|c|}{0.7910} & \multicolumn{2}{|c|}{0.3030} \\
\hline$p_{2}$ & \multicolumn{2}{|c|}{0.0257} & \multicolumn{2}{|c|}{0.8937} & \multicolumn{2}{|c|}{0.4732} & \multicolumn{2}{|c|}{0.7770} \\
\hline
\end{tabular}


concentrated flow to the splitting device (Y-connector). Apparently, this objective was attained only when the volume of water exceeded $100 \mathrm{~mL}$. Thus, it is reasonable to recommend that the sample splitter be used only on suspensions of volume greater than 250$300 \mathrm{~mL}$.

The prototype sample splitter was efficient in producing representative samples at both outlets $\mathrm{A}$ and B for all three artificial suspensions tested $-2,10$ and 50 $\mathrm{g} \mathrm{L}^{-1}$ of total solids (Table 5). Compared to the manual

Table 5 - Concentration of total solids in five samples (S1, S2, ..., S5) obtained using the prototype sample splitter from three artificial suspensions with a known concentration of total solids of 2, 10 and $50 \mathrm{~g} \mathrm{~L}^{-1}$. Statistics: SD = standard deviation, $\mathrm{CV}=$ coefficient of variation, $\mathrm{pME}=$ percentage mean estimation error, $t_{1}$ and $t_{2}=$ one and two-sample $t$-test statistic, $p_{1}$ and $p_{2}=p$-value of the $t_{1}$ and $t_{2}$-test.

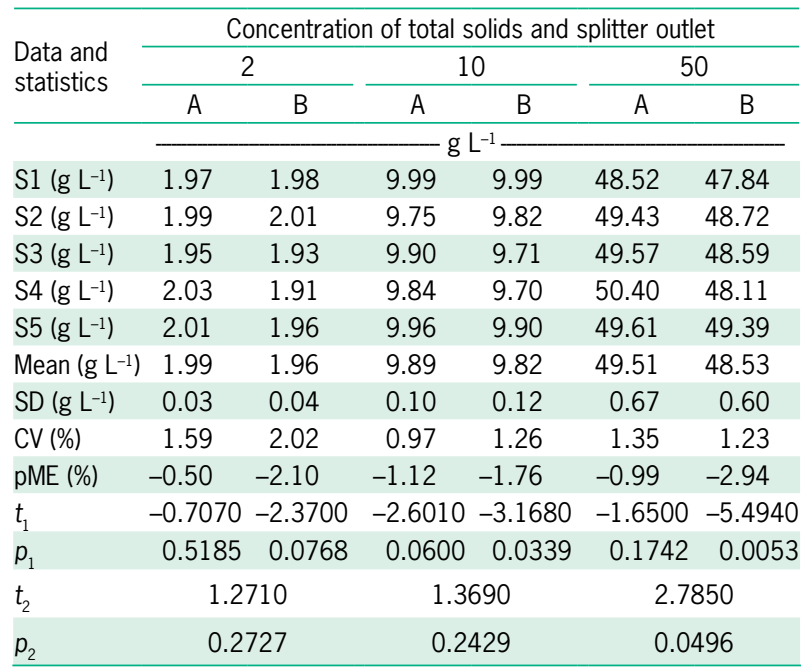

sampling method, the absolute errors were considerably small $(\mathrm{pME}<|5 \%|)$, as well as the variation between the repetitions $(\mathrm{CV}<3 \%)$. The occurrence of a consistent trend of negative estimation errors, indicated even by the $t$-test statistic, means that it is possible to correct the estimated concentration of total solids with a high degree of confidence. In addition, this underestimation can be avoided or minimized by adopting additional care during the splitting operation. We observed that, during the pouring of the suspension into the splitter's reservoir, larger diameter particles (sand) tend to remain inside the container where the suspension was stored. To avoid or minimize this loss of particles it is necessary to vigorously shake the container and pour the suspension rapidly into the reservoir. An additional practice is to wash the container using a known volume of distilled water and then pouring the new suspension into the splitter.

Samples produced by the splitter also were representative of the artificial suspensions tested in terms of sand content (Table 6). This occurred regardless of the splitter's outlet. The exception was for the artificial suspension with the lowest concentration of total solids, $2 \mathrm{~g} \mathrm{~L}^{-1}$, for which the estimation error was deemed too large. For all the five replicates, on average, the sand content was underestimated by about $50 \%$. We note, however, that this underestimation was not due to the sample splitting process itself. It resulted from the issue reported above, that is, particles of larger diameter tend to remain inside the container where the suspension was stored. This loss of larger particles results in the underestimation of the sand content.

The estimation errors of the clay content in the samples of both outlets were considerably larger than those for the sand content (Table 7). Errors were especially large for the artificial suspension with 2.00

Table 6 - Sand content in the total solids of five samples (S1, S2, .., S5) obtained using the prototype sample splitter from three artificial suspensions with a known concentration of total solids of 2,10 and $50 \mathrm{~g} \mathrm{~L}^{-1}$. Statistics: $\mathrm{SD}=$ standard deviation, $\mathrm{CV}=$ coefficient of variation, $\mathrm{pME}=$ percentage mean estimation error, $t_{1}$ and $t_{2}=$ one and two-sample $t$-test statistic, $p_{1}$ and $p_{2}=p$-value of the $t_{1}$ and $t_{2}$-test.

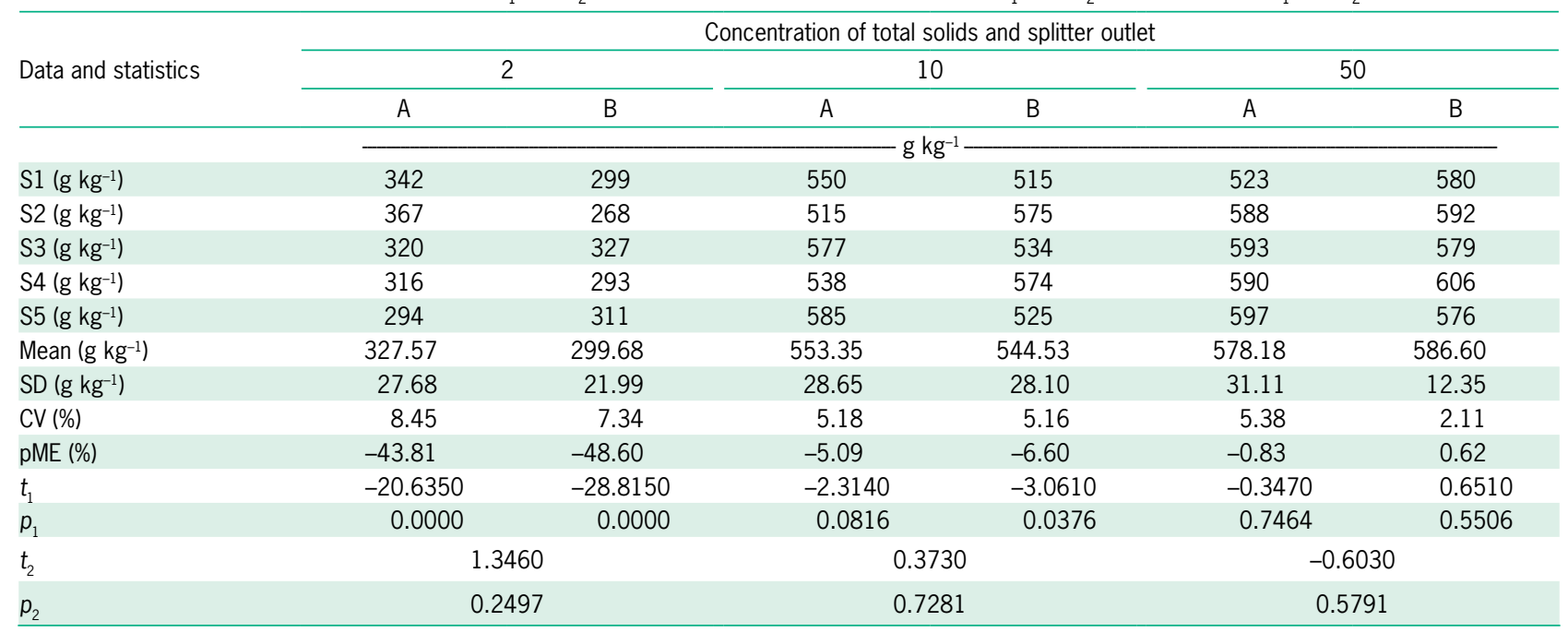


Table 7 - Clay content in the total solids of five samples (S1, S2, ..., S5) obtained using the prototype sample splitter from three artificial suspensions with a known concentration of total solids of 10 and $50 \mathrm{~g} \mathrm{~L}^{-1}$. Statistics: $\mathrm{SD}=$ standard deviation, $\mathrm{CV}=$ coefficient of variation, $\mathrm{pME}=$ percentage mean estimation error, $t_{1}$ and $t_{2}=$ one and two-sample t-test statistics, $p_{1}$ and $p_{2}=p$-value of the $t_{1}$ and $t_{2}$-test.

\begin{tabular}{|c|c|c|c|c|}
\hline \multirow{3}{*}{ Data and statistics } & \multicolumn{4}{|c|}{ Concentration of total solids and splitter outlet } \\
\hline & \multicolumn{2}{|c|}{10} & \multicolumn{2}{|c|}{50} \\
\hline & A & $B$ & A & $\mathrm{B}$ \\
\hline & \multicolumn{4}{|c|}{$\mathrm{g} \mathrm{kg}^{-1}$} \\
\hline $\mathrm{S} 1\left(\mathrm{~g} \mathrm{~kg}^{-1}\right)$ & 68 & 78 & 87 & 93 \\
\hline $\mathrm{S} 2\left(\mathrm{~g} \mathrm{~kg}^{-1}\right)$ & 72 & 60 & 90 & 94 \\
\hline S3 $\left(\mathrm{g} \mathrm{kg}^{-1}\right)$ & 60 & 91 & 91 & 89 \\
\hline S4 $\left(\mathrm{g} \mathrm{kg}^{-1}\right)$ & 84 & 60 & 92 & 78 \\
\hline $\mathrm{S} 5\left(\mathrm{~g} \mathrm{~kg}^{-1}\right)$ & 83 & 83 & 83 & 85 \\
\hline Mean $\left(\mathrm{g} \mathrm{kg}^{-1}\right)$ & 73.39 & 74.47 & 88.77 & 87.90 \\
\hline $\mathrm{SD}\left(\mathrm{g} \mathrm{kg}^{-1}\right)$ & 10.25 & 13.92 & 3.57 & 6.57 \\
\hline CV (\%) & 13.96 & 18.69 & 4.02 & 7.47 \\
\hline pME (\%) & -17.54 & -16.32 & -0.2600 & -1.2300 \\
\hline$t_{1}$ & -3.4080 & -2.3330 & -0.1470 & -0.3730 \\
\hline$p_{1}$ & 0.0271 & 0.0799 & 0.8904 & 0.7279 \\
\hline$t_{2}$ & \multicolumn{2}{|c|}{-0.1150} & \multicolumn{2}{|c|}{0.2460} \\
\hline$\underline{p_{2}}$ & \multicolumn{2}{|c|}{0.9138} & \multicolumn{2}{|c|}{0.8178} \\
\hline
\end{tabular}

$\mathrm{g} \mathrm{L}^{-1}$ of total solids. This occurred because, for the soil material used, the quantity of clay in the resulting samples was below the detection limit of the analytical method used. When the concentration of total solids was higher (10 and $50 \mathrm{~g} \mathrm{~L}^{-1}$ ), the percentage estimation error was lower, its significance decreasing as the concentration of total solids increased.

Further assessments of the sample splitter should be carried out using a wider range of concentrations of total solids and particle size distributions. This is necessary to guarantee its efficiency under different conditions, especially if the manual sampling method proves to underestimate soil losses even when the solid fraction is dominated by fine particles (clay).

\section{Conclusions}

The manual runoff sampling method used in Brazil is unsuitable for the sampling of suspensions containing total solids with a prevalence of coarse particles (sand $>500 \mathrm{~g} \mathrm{~kg}^{-1}$ ). In addition to the concentration underestimates of total solids, there is a large variation in the estimated values. This means that the sampling method constitutes an important element of variation in the results of soil erosion monitoring studies. This variation adds to the uncertainty arising from other sources already described in the literature.

The prototype sample splitter that we developed proved to be an efficient producer of samples from artificial suspension with different concentrations of total solids without changing the particle size distribution. This efficiency is clear and consistent mainly for suspension volumes above $250-300 \mathrm{~mL}$ and concentrations of total solids greater than $2 \mathrm{~g} \mathrm{~L}^{-1}$. Thus, if the problems that we identify in the manual sampling method are also found by other research groups, the prototype we developed can be considered a reasonable alternative.

\section{Acknowledgments}

We are grateful to Dr. Pablo Miguel (Federal University of Pelotas - UFPel) who took part in data acquisition. We are grateful to two anonymous reviewers for helpful comments on the original version of the manuscript as well as the critical comments by another three anonymous reviewers on an earlier version of the manuscript. The research for this paper was financially supported by the Coordination for the Improvement of Higher Level Personnel (CAPES), and the Brazilian National Council for Scientific and Technological Development (CNPq).

\section{Authors' Contributions}

Conceptualization: Samuel-Rosa, A. Data acquisition: Samuel-Rosa, A.; Moura-Bueno, J.M.; Dalmolin, R.S.D. Data analysis: Samuel-Rosa, A.; Moura-Bueno, J.M. Design of methodology: SamuelRosa, A. Writing and editing: Samuel-Rosa, A.; MouraBueno, J.M.; Dalmolin, R.S.D.

\section{References}

Anache, J.A.A.; Wendland, E.C.; Oliveira, P.T.; Flanagan, D.C.; Nearing, M.A. 2017. Runoff and soil erosion plot-scale studies under natural rainfall: a meta-analysis of the Brazilian experience. Catena 152: 29-39. https://doi.org/10.1016/j. catena.2017.01.003

Boix-Fayos, C.; Martínez-Mena, M.; Arnau-Rosalén, E.; CalvoCases, A.; Castillo, V.; Albaladejo, J. 2006. Measuring soil erosion by field plots: understanding the sources of variation. Earth-Science Reviews 78: 267-285. https://doi.org/10.1016/j. earscirev.2006.05.005

Capel, P.D.; Nacionales, F.C.; Larson, S.J. 1995. Precision of a Splitting Device for Water Samples. U.S. Geological Survey, Sacramento, CA, USA. https://doi.org/10.3133/ofr95293

Ciesiolka, C.A.A.; Yu, B.; Rose, C.; Ghadiri, H.; Lang, D.; Rosewell, C. 2006. Improvement in soil loss estimation in USLE type experiments. Journal of Soil and Water Conservation 61: 223-229.

Cogo, N.P.; Moldenhauer, W.C.; Foster, G.R. 1984. Soil loss reductions from conservation tillage practices. Soil Science Society of America Journal 48: 368. https://doi.org/10.2136/ sssaj1984.03615995004800020029x

Corrêa, E.A.; Moraes, I.C.; Pinto, S.D.A.F.; Lupinacci, C.M. 2016. Soil losses, soil loss ratio and cover management factor of sugarcane: a first approach. Revista do Departamento de Geografia 32: 72-87. https://doi.org/10.11606/rdg.v32i0.116671 (in Portuguese, with abstract in English). 
Eltz, F.L.F.; Mehl, H.U.; Reichert, J.M. 2001. Interrill soil and water losses in an Ultisol under four rainfall patterns. Revista Brasileira de Ciência do Solo 25: 485-493. https://doi. org/10.1590/S0100-06832001000200024 (in Portuguese, with abstract in English).

García-Ruiz, J.M.; Beguería, S.; Nadal-Romero, E.; GonzálezHidalgo, J.C.; Lana-Renault, N.; Sanjuán, Y. 2015. A metaanalysis of soil erosion rates across the world. Geomorphology 239: 160-173. https://doi.org/10.1016/j.geomorph.2015.03.008

Horowitz, A.J.; Smith, J.J.; Elrick, K.A. 2001. Selected laboratory evaluations of the whole-water sample-splitting capabilities of a prototype fourteen-liter teflon churn splitter. U.S. Geological Survey, Atlanta, GA, USA. https://doi.org/10.3133/ofr01386

Huang, Y.; Zhao, H.; Li, F.; Yuan, P.; Wang, W.; Zhang, G. 2019. Measurement errors on sediment concentration from traditional runoff collection tanks and its correction possibility. International Journal of Agricultural and Biological Engineering 12: 77-83. https://doi.org/10.25165/j.ijabe.20191203.4208

Kinnell, P.I.A. 2016. A review of the design and operation of runoff and soil loss plots. Catena 145: 257-265. https://doi. org/10.1016/j.catena.2016.06.013

Lang, R.D. 1992. Accuracy of two sampling methods used to estimate sediment concentrations in runoff from soil-loss plots. Earth Surface Processes and Landforms 17: 841-844. https:// doi.org/10.1002/esp.3290170809

Lanzanova, M.E.; Eltz, F.L.F.; Silveira Nicoloso, R.; Cassol, E.A.; Bertol, I.; Amado, T.J.C.; Girardello, V.C. 2013. Residual effect of soil tillage on water erosion from a typic paleudalf under long-term no-tillage and cropping systems. Revista Brasileira de Ciência do Solo 37: 1689-1698. https://doi.org/10.1590/ S0100-06832013000600025

Merten, G.H.; Araújo, A.G.; Biscaia, R.C.M.; Barbosa, G.M.C.; Conte, O. 2015. No-till surface runoff and soil losses in southern Brazil. Soil and Tillage Research 152: 85-93. https:// doi.org/10.1016/j.still.2015.03.014

Nearing, M.A.; Govers, G.; Norton, L.D. 1999. Variability in soil erosion data from replicated plots. Soil Science Society of America Journal 63: 1829-1835. https://doi.org/10.2136/ sssaj1999.6361829x

Nikkami, D. 2012. Investigating sampling accuracy to estimate sediment concentrations in erosion plot tanks. Turkish Journal of Agriculture and Forestry 36: 583-590. https://doi. org/10.3906/tar-1110-27
Panagos, P.; Borrelli, P.; Meusburger, K.; Yu, B.; Klik, A.; Lim, K.J.; Yang, J.E.; Ni, J.; Miao, C.; Chattopadhyay, N.; Sadeghi, S.H.; Hazbavi, Z.; Zabihi, M.; Larionov, G.A.; Krasnov, S.F.; Gorobets, A.V.; Levi, Y.; Erpul, G.; Birkel, C.; Hoyos, N.; Naipali, V.; Oliveira, P.T.S.; Bonilla, C.A.; Meddi, M.; Nel, W.; Dashti, H.A.; Boni, M.; Diodato, N.; Oost, K.V.; Nearing, M.; Ballabio, C. 2017. Global rainfall erosivity assessment based on high-temporal resolution rainfall records. Scientific Reports 7: 4175. https://doi.org/10.1038/s41598-017-04282-8

Poesen, J. 2018. Soil erosion in the Anthropocene: research needs. Earth Surface Processes and Landforms 43: 64-84. https://doi. org/10.1002/esp.4250

Silva, R.M.; Santos, C.A.G.; Santos, J.Y.G. 2018. Evaluation and modeling of runoff and sediment yield for different land covers under simulated rain in a semiarid region of Brazil. International Journal of Sediment Research 33: 117-125. https://doi.org/10.1016/j.ijsrc.2017.04.005

Tengberg, A.; Stocking, M.; Dechen, S.C.F. 1997. The impact of erosion on soil productivity: an experimental design applied in São Paulo state, Brazil. GeografiskaAnnaler: Series A. Physical Geography 79: 95-107. https://doi.org/10.1111/j.04353676.1997.00009.x

Todisco, F; Vergni, L.; Mannocchi, F.; Bomba, C. 2012. Calibration of the soil loss measurement method at the Masse experimental station. Catena 91: 4-9. https://doi.org/10.1016/j. catena.2011.02.003

Veiga, M.; Wildner, L.P. 1993. Manual for the installation and conduction of soil loss experiments = Manual para la instalación y conducción de experimentos de pérdida de suelos. FAO Regional Office for Latin America and the Caribbean, Santiago, Chile (in Spanish).

Volk, L.B.S.; Cogo, N.P. 2009. Relationships between size of eroded sediments, runoff velocity, surface roughness created by tillage, and size of aggregates in a soil submitted to different managements. Revista Brasileira de Ciência do Solo 33: 14591471. https://doi.org/10.1590/S0100-06832009000500036 (in Portuguese, with abstract in English).

Zöbisch, M.A.; Klingspor, P.; Oduor, A.R. 1996. The accuracy of manual runoff and sediment sampling from erosion plots. Journal of Soil and Water Conservation 51: 231-233. 